остракод Clavofabella reticristata, Leptobolbina quadricuspidata и Craspedobolbina lembodes в разрезе скв. Охесаape, где эта граница обоснована литологическими и палеонтологическими критериями.

\title{
ЛИТЕРАТ УРА
}

Гайлите Л. К., Ры бников а М. В., Ульст Р. Ж. 1967. Стратиграфия, фауна и условия образования силурийских пород Средней Прибалтики. Рига.

Л а п и н ск а с П. П. 1965. Метабентониты нижнего силура Литвы. В сб.: Геология н нефтеносность палеозоя Южной Прибалтики, вып. 1. Вильнюс.

П а ш к е в и чюс И. Ю. 1962 . К вопросу стратиграфии силурийских отложений по данным глубокого бурегия в юго-западной части Литовской CCP. LTSR Aukšt. m-lų Mokslo darbai, Geogr. ir geol., 1.

П а ш к в и ч с И. Ю. 1968. Биостратиграфия и корреляция силурийских терригенных и карбонатных отложений Южной Прибалтики. В сб.: Стратиграфия нижнего палеозоя Прибалтики и корреляция с другими регионами. Вильнюс.

Сарв Л. 1971. Силурийские остракоды в разрезе скважины Охесааре. Изв. АН ЭССР, Хим. Геол., 20, № 4.

$\begin{array}{cc}\text { Институт геологии } & \text { Поступила в редакцию } \\ \text { Академии наук Эстонской СCP } & \text { 1/VIII } 1972\end{array}$

EESTI NSV TEADUSTE AKADEEMIA TOIMETISED, 22. KOIDE

KEEMIA * GEOLOOGIA. 1973. NR. 1

ИЗВЕСТИЯ АКАДЕМИИ НАУК ЭСТОНСКОИ ССР. ТОМ 22

ХИМИЯ * ГЕОЛОГИЯ. 1973, Nㅡ 1

\section{ИЗМЕРЕНИЕ ПРИРОДНОГО С 14 НА ОДНОКАНАЛЬНОИ СЦИНТИЛЛЯЦИОННОЙ УСТАНОВКЕ ИНСТИТУТА ГЕОЛОГИИ АН ЭССР}

\author{
I.-M. PUNNING, R. RAJAMAE. LOODUSLIKU ${ }^{14} \mathrm{C}$ MAARAMINE ENSV TA GEOLOOGIA INSTITUUDIS \\ OHEKANALILISE STSINTILLATSIOONLOENDI ABIL
J.-M. PUNNING, R. RAJAMAEE, DETERMINATION OF THE NATURAL "C BY ONE-CHANNEL SCINTILLATION COMPUTER AT THE INSTITUTE OF GEOLOGY OF THE ACADEMY OF SCIENCES OF THE ESSR

В настоящее время метод определения абсолютного (радиометрического) возраста по радиоактивному углероду $\left(\mathrm{C}^{14}\right)$ находит широкое применение в четвертичной геологии, археологии, палеонтологии и других естественных и исторических науках. Хотя определяемый возрастной диапазон охватывает только последние 50-55 тысяч лет, данные датировки по $\mathrm{C}^{14}$ нашли широкое применение при изучении разных геологических событий, вызывавших изменение в процессах седиментации. Учитывая тематику Института Геологии АН ЭССР, оказалось целесообраз. ным создать радиоуглеродную установку при институте. Как наиболее подходящий, нами был выбран сцинтилляционный вариант радиоуглеродного метода, аппаратура которого более компактна, количество измеряемого углерода и соответственно возрастная граница больше. 
Для извлечения посторонних примесей, вносимых в исследуемый образец после его выхода из обменного резервуара, используется кислотно-щелочно-пирофосфатная обработка образцов (Пуннинг и др., 1966). В качестве счетного препарата нами был выбран бензол, который, помимо хороших сцинтилляционных свойств, обладает высоким содержанием углерода. Бензол синтезируется из обугленного образца путем тримеризации ацетилена на алюмосиликатнованадиевом катализаторе.

Схема синтеза бензола следующая:

$$
\begin{gathered}
2 \mathrm{C}+2 \mathrm{Li} \stackrel{550 \circ \mathrm{C}}{\longrightarrow} \mathrm{Li}_{2} \mathrm{C}_{2}, \\
\mathrm{Li}_{2} \mathrm{C}_{2}+2 \mathrm{H}_{2} \mathrm{O} \longrightarrow 2 \mathrm{LiOH}+\mathrm{C}_{2} \mathrm{H}_{2}, \\
3 \mathrm{C}_{2} \mathrm{H}_{2} \stackrel{\text { катал. }}{\longrightarrow} \mathrm{C}_{6} \mathrm{H}_{6} .
\end{gathered}
$$

Ацетилен, полученный в результате разложения карбида лития водой. очищается, осушается и впускается в цельностеклянную систему на предварительно прокаленный в вакууме катализатор. По окончании тримеризации сосуд с катализатором нагревается в течение 20 минут в трубчатой печи при температуре $300^{\circ} \mathrm{C}$ и выделившийся бензол замораживается в ловушке с жидким азотом. Полученный бензол перегоняется над металлическим натрием. Выход бензола по ацетилену около $95 \%$.

Сцинтиллятор приготавливается из следующих компонентов: синтезированного из образца бензола $(90 \%)$, м-ксилола $(10 \%)$, РРО (4 г/л) и PОРОР $(0,12 / \Omega)$. Сцинтиллятор вводится в алюминиевую кювету с окном из бескалиевого стекла, оптический контакт которого с фотокатодом ФЭУ достигается при помощи силиконового масла.

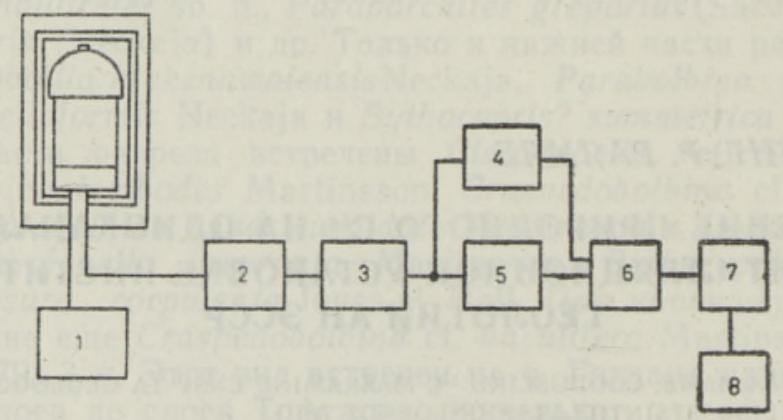

Блок-схема одноканальной сцинтилляционной установки для радиоуглеродного определения абсолютного возраста.

1 - высоковольтный выпрямитель ВС-22; 2 - катодный повторитель; 3 - усилитель УИС-2м; 4 - дискриминатор верхнего порога; 5 - дискриминатор нижнего порога; 6 - схема антисовпадений; 7 - пересчетный прибор ПП-16; 8 - электронный самописец ЭПП-09.

Регистрация активности природного углерода осуществляется одноканальной сцинтилляционной установкой, блок-схема которой приведена на рисунке. Вся установка собрана из стандартных блоков отечественного производства.

Для защиты ФЭУ и измеряемого препарата от космического излучения использована цилиндрическая свинцовая защита с толщиной стенок 50 мм и ртутная защита толщиной $30 \mathrm{мм}$. 
Для питания ФЭУ применен стабилизированный выпрямитель высокого напряжения ВС-22. Питание ФЭУ осуществляется через делитель напряжения, причем фотокатод заземлен и сигнал снимается с последнего динода. Импульсы с ФЭУ поступают на катодный повторитель типа Уайта, выполненный на лампе 6 Н24П. В качестве усилителя использован спектрометрический усилитель УИС-2м. Амплитудная селекция импульсов, поступающих из усилителя, производится двумя дифференциальными дискриминаторами БД-2, работающими в интегральном режиме и приспособленными для пропускания импульсов с амплитудой выше уровня дискриминатора нижнего порога и ниже уровня дискриминатора верхнего порога. Регистрация импульсов производится пересчетным приборпм ПП-16. Для контроля счета параллельно через схему управления включен электронный самописец ЭПП-09, регистрирующий отрезок времени, соответствующий набору определенного числа импульсов. Установка питается через электромагнитный стабилизатор напряжения C- 0,75 .

Для контроля стабильности аппаратуры и условий измерения проводятся ежедневные проверки сцинтилляционной эффективности сцинтиллятора внешним $\gamma$-излучателем $\mathrm{Co}^{60}$, стабильности коэффициента усиления усилителя и порогов дискриминаторов.

При использовании одноканальной сцинтилляционной установки, для регистрации низкоэнергетического излучения особое значение имеет качество фотоэлектронных умножителей. Нами исследовались фотоэлектронные умножители из серии специально отобранных на заводе экземпляров ФЭУ-93 и ФЭУ-97. Критериями отбора служили коэффициент умножения по паспортным данным, измеренный энергетический эквивалент собственных шумов и стабильность работы при долговременной эксплуатации. Для установления уровня собственных шумов каждого ФЭУ измерялись интегральные спектры амплитуды собственных шумов и их энергетический эквивалент при скорости счета 10 имn./мин (Лийва и др., 1966). В качестве опорной энергетической точки использовались максимумы $\gamma$-спектра $\mathrm{Co}^{60}$ при энергиях 1,17 и 1,33 Мэв и спектра $\mathrm{Cs}^{137}$ при энергии 0,661 Мэв. Полученные данные приведены в табл. 1.

Tаблица 1

\begin{tabular}{c|c|c|c|c}
\hline Тил ФЭу & $\begin{array}{c}\text { Номер } \\
\text { экземпляра }\end{array}$ & $\begin{array}{c}\text { Число } \\
\text { дннодов }\end{array}$ & $\begin{array}{c}\text { Напряжение } \\
\text { питання, } \boldsymbol{8}\end{array}$ & $\begin{array}{c}\text { Энергетический } \\
\text { эквивалент, Кэв }\end{array}$ \\
\hline ФЭУ-97 & 350 & 14 & 1360 & 4,3 \\
ФЭУ-97 & 226 & 14 & 1300 & 4,9 \\
ФЭУ-97 & 176 & 14 & 1000 & 6,3 \\
& & & 1080 & 4,8 \\
& & & 1160 & 4,4 \\
& & & 1260 & 4,5 \\
& & & 1360 & 4,4 \\
ФЭУ-93 & 131 & 12 & 1460 & 4,3 \\
S12FS50 & 21231 & 12 & 1500 & 4,3 \\
\end{tabular}

Среди исследованных экземпляров наилучшим оказался ФЭУ-97 № 176, отличающийся стабильностью работы при длительной эксплуатации.

Для выбора оптимального счетного режима снимались дифференциальные спектры стандартного и фонового препаратов. В результате был выбран режим, при котором напряжение на ФЭУ равно 1360 в, коэффициент усиления УИС-2м - 280, нижний и верхний пороги анализатора 
соответственно 14 и 40 в, что в энергетической шкале соответствует величинам 40 и 110 Кэв. Показатели счета, полученные при этом режиме счета, приведены в табл. 2.

Таблица 2

Зависимость счетных характеристик от объема сцинтиллятора

\begin{tabular}{|c|c|c|c|c|c|}
\hline $\begin{array}{l}\text { Объем } \\
\text { сцинтил- } \\
\text { лятора, } \mu \Omega\end{array}$ & $\begin{array}{c}\text { Содержание } \\
\mathrm{C}^{14} \text { в сцин- } \\
\text { тилляторе, } \\
2\end{array}$ & $\begin{array}{c}\text { Фон, } \\
\text { uмn./мuн }\end{array}$ & $\begin{array}{c}\text { Чистый счет } \\
\text { эталона, } \\
\text { имл./мин }\end{array}$ & $\begin{array}{c}\text { Показатель } \\
\text { качества }\end{array}$ & $\begin{array}{c}\text { Эффективность } \\
\text { регистрации } \\
\text { C }^{14}, \%\end{array}$ \\
\hline $\begin{array}{r}5 \\
7 \\
10 \\
14\end{array}$ & $\begin{array}{r}3,96 \\
5,55 \\
7,90 \\
11,09\end{array}$ & $\begin{array}{l}3,18 \\
3,41 \\
3,75 \\
4,71\end{array}$ & $\begin{array}{l}22,6 \\
31,6 \\
49,5 \\
62,2\end{array}$ & $\begin{array}{l}12,7 \\
17,1 \\
25,6 \\
28,7\end{array}$ & $\begin{array}{l}40,1 \\
40,0 \\
44,0 \\
40,0\end{array}$ \\
\hline
\end{tabular}

При вычислении эффективности регистрации $\mathrm{C}^{14}$ за основу принята удельная активность «современного» углерода, равная $14,24 \pm 0,07$ имп./мин (Karlen и др., 1969).

Установка работает стабильно, воспроизводимость серий отдельных измерений при длительной эксплуатации находится в пределах $\pm 2 \sigma$. Так как контрольные датировки образцов, возраст которых был ранее определен в других радиоуглеродных лабораториях, доказали достоверность применяемой методики, описанная установка применяется для серийных определений.

\section{ЛИТЕРАТУРА}

Лйй а А., Ильвес Э., Пуннинг Я.-М. 1966. Энергетический эквивалент собственных шумов некоторых фотоэлектронных умножителей. Изв. АН ЭССР, Сер. физ.-матем. и техн. н., XV, № 1.

Пуннинг Я.-М., Ильвес Э., Л й в а А. 1966. Датирование древних образцов радиоуглеродным методом. Изв. АН ЭССР, Сер. биол. н.. XV, № 4.

Karlen I., Olsson I. U., Kåliberg P., Kil ic ci S. 1964. Absolute Determination of the Activity of Two Dating Standards. Arkiv geofys., 4, Nr. 22.

Институт геологии

Академии начк Эстонской ССР
Поступила в редакцию 9/VIII 1972 